\title{
High-Frequency Transfection of Mouse FM3A Mammary Carcinoma Cells in Suspension Culture with Plasmid DNA
}

\author{
Tadatomo Ogawa ${ }^{1}$, Masao Hyodo ${ }^{2}$, Seiji Ihara'2, Masataka Takekoshi², \\ Kaori Minato ${ }^{2}$ and Kenshi Suzuki ${ }^{2}$ \\ ${ }^{1}$ Cosmetics Laboratory, Kanebo, Ltd., 3-28 5-chome Kotobuki-cho, Odawara, \\ Kanagawa 250 and ${ }^{2}$ Department of Molecular Biology, Tokai University School \\ of Medicine, Boseidai, Isehara, Kanagawa 259-11, Japan
}

\begin{abstract}
High-frequency transfection of mouse FM3A cells, grown in suspension, with plasmid pSV2neo DNA was achieved by incubation of the cells with DNA plus polybrene for $6 \mathrm{~h}$ followed by an osmotic shock with a hypertonic $\mathrm{NaCl}$ solution. When incubated for $20 \mathrm{~min}$ at $34^{\circ} \mathrm{C}, \mathrm{FM} 3 \mathrm{~A}$ cells showed resistance to the osmolarity change from 0.1 to $9.0 \% \mathrm{NaCl}$ in the medium. Within this concentration range, 5-7\% gave the highest efficiency of transfection. Both linear and circular forms of plasmid DNA produced transformants with equal efficiency. This method was simple, reproducible, and carrier DNA was not required. The efficiency was about 100 times higher than that of the method with DNA-calcium phosphate precipitates. Transformed cells were stable and different numbers of plasmid DNA copies were detected.
\end{abstract}

Recent development of methods of DNA-mediated gene transfer, together with the molecular cloning of genes and DNA-sequencing, has made it possible to identify various genes of mammalian cells. Many genes coding for enzymes have been isolated by complementation of the defective gene in somatic cell mutants $(10,15)$, oncogenes by alteration in growth properties of the transfected cells (22), and a gene coding for cellular growth factor (25) and one for receptor (13) by detecting the products expressed in the transfected cells. For DNA transfection to cultured mammalian cells, the DNA-calcium phosphate method $(6,14)$ has been widely used. This method has been shown to be simple, reproducible, and highly efficient. However, the rate of gene-transfer by this method is highly dependent on the cell line used as the recipient.

Mouse mammary carcinoma FM3A cells have been established as a suspension culture and are frequently used for studies of somatic cell genetics. Many types of mutants have been isolated from this cell line and characterized by properties such as altered sensitivity to drugs $(1,12)$, nutritional requirements $(2,3)$, or temperaturesensitivity $(2,8,19,24)$. However, since the DNA-calcium phosphate method does not usually result in high-efficiency transfection with this cell, further analysis of interesting mutants at the molecular level has been prevented.

Other methods of gene-transfer include the use of DEAE-dextran (17), liposomes (18), and protoplast fusion (21). However, these methods are not suitable for mouse FM3A cells because of the low frequency of obtaining stable transformants. Highvoltage electric pulses seemed to be successful (7), but this method requires special, expensive equipment. Recently Kawai and Nishizawa (11) and Chaney et al. (5) 
reported a simple method of transfection by treatment of cells with DNA plus polybrene followed by a high concentration of dimethyl sulfoxide (DMSO). We have examined this method and found that the frequency of transfection was better than that of the DNA-calcium phosphate method. To improve this method, we tried several alternatives to DMSO treatment to increase the cell permeability. Our results show that osmotic shock with a hypertonic solution, $5-7 \% \mathrm{NaCl}$ in medium, causes high-frequency transfection.

\section{MATERIALS AND METHODS}

Cells and plasmid DNA. FM3A cells, F28-7 clone, derived from mouse mammary carcinoma (12), were grown in suspension in Eagle's minimum essential medium (MEM, Nissui Seiyaku Co.) supplemented with $5 \%$ calf serum (GIBCO) and $0.1 \%$ Bactopeptone (Difco Lab.) in an atmosphere of $5 \% \mathrm{CO}_{2}$ at high humidity. Incubation of cells was at $34^{\circ} \mathrm{C}$.

The plasmid pSV2neo DNA (23) has a promoter sequence of virus SV40 ligated to the bacterial aminoglycosyl 3' phosphotransferase (neo) gene which to bacteria confers resistance to neomycin/kanamycin and to mammalian cells resistance to the antibiotic G418 (Geneticin, GIBCO). Plasmid DNA was prepared from plasmid-harboring E. coli (HB 101) by the alkaline lysis method (16) and purified by CsCl-ethidium bromide equilibrium centrifugation (16). Plasmid DNAs were linearized by digestion with restriction endonuclease EcoR1 (Takara Shuzo Co.), and the products were confirmed by agarose gel electrophoresis (16).

DNA transfection and selection of transformants. Log-phase cells were collected by centrifugation and aliquots of $1 \times 10^{6}$ cells were suspended in $1 \mathrm{ml}$ of culture medium in a plastic tube (Falcon tube 2095). Then $30 \mu \mathrm{g}$ of polybrene (Aldrich, dissolved at $1 \mathrm{mg} / \mathrm{ml}$ in culture medium) and 1-10 $\mu \mathrm{g}$ of DNA (dissolved at $0.5 \sim 1.0 \mathrm{mg} / \mathrm{ml}$ in $10 \mathrm{mM}$ Tris-Cl, $1 \mathrm{mM}$ EDTA, $\mathrm{pH}$ 7.6) were added to the cell suspension. The cells were incubated at $34^{\circ} \mathrm{C}$ for $6 \mathrm{~h}$ in a $\mathrm{CO}_{2}$ incubator with occasional gentle mixing. After incubation, cells were collected by a brief centrifugation and then suspended in $3 \mathrm{ml}$ MEM or Hanks' solution which contained $5 \% \mathrm{NaCl}$ (final concentration) but no serum. MEM and Hanks' solution gave the same results. Cells were incubated for a further $20 \mathrm{~min}$ at $34^{\circ} \mathrm{C}$, collected by centrifugation, and suspended in $5 \mathrm{ml}$ of culture medium. The cell suspension was transferred to a $60 \mathrm{~mm}$ plastic dish and incubated for $48-72 \mathrm{~h}$ in a $\mathrm{CO}_{2}$ incubator.

For the selection of transformants, $1-3 \times 10^{5}$ surviving cells were plated in a $60 \mathrm{~mm}$ plastic dish with agar medium which contained $0.3 \%$ agar and $0.5 \mathrm{mg} / \mathrm{ml} \mathrm{G} 418$ (as an active agent) in MEM supplemented with $10 \%$ calf serum. Agar plates were incubated for 2 weeks and colonies were scored. With this selection procedure, fetal calf serum could not be used since some small colonies developed from cells which had not been transfected with DNA. No such background was observed when calf serum was used.

Characterization of transformed cells. To test the stability of the transformed cells, colonies in the agar plates were transferred to culture medium which contained $0.5 \mathrm{mg} / \mathrm{ml}$ of G418 and incubated for 2 weeks. Then the cells were maintained in the culture medium without selection for 2 months. Sensitivity of these cells to G418 was examined by plating $1 \times 10^{4}$ cells in a plastic multiwell dish which contained $1.5 \mathrm{ml}$ of the culture medium and variable amounts of G418. The plates were incubated for 6 days and the cell numbers were determined.

To examine the plasmid DNA sequence integrated in the chromosomal DNA, Southern 
blot hybridization was performed. Cellular DNAs were extracted from isolated nuclei as described by Jariwalla et al. (9). DNAs were digested at $37^{\circ} \mathrm{C}$ for $2 \mathrm{~h}$ with restriction enzyme EcoR1 (6 units/ $\mu$ g DNA). Digested DNAs (15 $\mu \mathrm{g} /$ lane) were electrophoresed in $0.6 \%$ agarose gel, stained with ethidium bromide, photographed, denatured, and blotted onto nylon membrane (Hybond-N, Amersham) by electrophoresis. pSV2neo DNA (25 ng) was labeled overnight at room temperature with random primers (Amersham Multiprime DNA Labeling System) and $55 \mu \mathrm{Ci}$ of $\left[\alpha^{-32} \mathrm{P}\right] \mathrm{dCTP}(3,000 \mathrm{Ci} / \mathrm{mmol})$. Hybridization was performed overnight at $65^{\circ} \mathrm{C}$ in Denhardt's solution (16) containing $0.5 \%$ sodium dodecylsulfate (SDS) and $20 \mu \mathrm{g} / \mathrm{ml}$ of heat denatured salmon sperm DNA. The membrane was washed at $65^{\circ} \mathrm{C}$ three times in $2 \times \mathrm{SSC}$ (SSC; $0.15 \mathrm{M} \mathrm{NaCl}, 0.015 \mathrm{M}$ sodium citrate) containing $0.5 \%$ SDS, and once in $0.1 \times$ SSC containing $0.5 \%$ SDS. Dried membrane was exposed to Kodak XAR-5 film at $-70^{\circ} \mathrm{C}$ for about $80 \mathrm{~h}$ with an intensifing screen.

\section{RESULTS AND DISCUSSION}

The method of transfection with DNA-calcium phosphate precipitates, which is widely used with many cell lines, was quite inefficient with mouse FM3A cells. As shown in Table 1 , it gave only $3 \times 10^{-6}$ G418-resistant transformants with $5 \mu \mathrm{g}$ of linear pSV2neo DNA. The reason for this is not known, but the method seems to depend on the ability of the cells to take up the precipitates by phagocytosis. Since FM3A cells grow in suspension, their phagocytotic activity may be reduced. Sufficient contact of cells with the precipitates seems to occur on the surface of the plastic dish as observed microscopically. The same inefficiency of this method for FM3A cells has been reported by Hama-Inaba et al. (7).

We therefore examined the transfection method with polybrene as described by Kawai and Nishizuka (11) and Chaney et al. (5). This method employed incubation of the cells with DNA plus polybrene followed by treatment with $30 \%$ DMSO. However, FM3A cells were much more sensitive to DMSO than the cells used in those

TABLE 1. TRANSFECTION OF MOUSE FM3A CELLS WITH PSV2NEO DNA BY DIFFERENT METHODS

\begin{tabular}{|c|c|c|c|c|}
\hline \multirow{2}{*}{ Exp } & \multirow{2}{*}{ DNA } & \multicolumn{2}{|c|}{ Treatments } & \multirow{2}{*}{$\begin{array}{l}\mathrm{G} 418^{\mathrm{r}} \text { cell } \\
\text { per } 10^{6}\end{array}$} \\
\hline & & $1 \mathrm{st}$ & $2 \mathrm{nd}$ & \\
\hline 1 & linear & DNA + Ca-phosphate & $10 \%$ DMSO & 3 \\
\hline 2 & linear & DNA +Ca-phosphate & $5 \% \mathrm{NaCl}$ & 14 \\
\hline 3 & linear & DNA + polybrene & $15 \%$ DMSO & 42 \\
\hline 4 & linear & DNA + polybrene & $50 \%$ PEG 6000 & 46 \\
\hline 5 & linear & DNA+polybrene & $5 \% \mathrm{NaCl}$ & 284 \\
\hline 6 & supercoil & DNA + polybrene & $5 \% \mathrm{NaCl}$ & 310 \\
\hline 7 & -DNA & polybrene & $5 \% \mathrm{NaCl}$ & 0 \\
\hline 8 & linear & $5 \% \mathrm{NaCl}, 20 \mathrm{~min}$ & DNA + polybrene & 0 \\
\hline 9 & linear & DNA+ polybrene & $5 \% \mathrm{NaCl} \rightarrow 10 \%$ DMSO & 14 \\
\hline 10 & linear & DNA+polybrene & $5 \% \mathrm{NaCl} \rightarrow 50 \% \mathrm{PEG}$ & 9 \\
\hline
\end{tabular}

In experiments 1 and 2, DNA-calcium phosphate precipitates were produced by the method of Lewis et al. (14). The precipitates were added to the cells and the mixture was incubated for $8 \mathrm{~h}$. Then the cells were treated with $10 \%$ DMSO for $30 \min$ (Exp. 1) or with $5 \% \mathrm{NaCl}$ in MEM for $20 \mathrm{~min}$ (Exp. 2). In experiments 3-10, cells were treated as described in MATERIALS AND METHODS except that some specifications were added as described in the Table. 

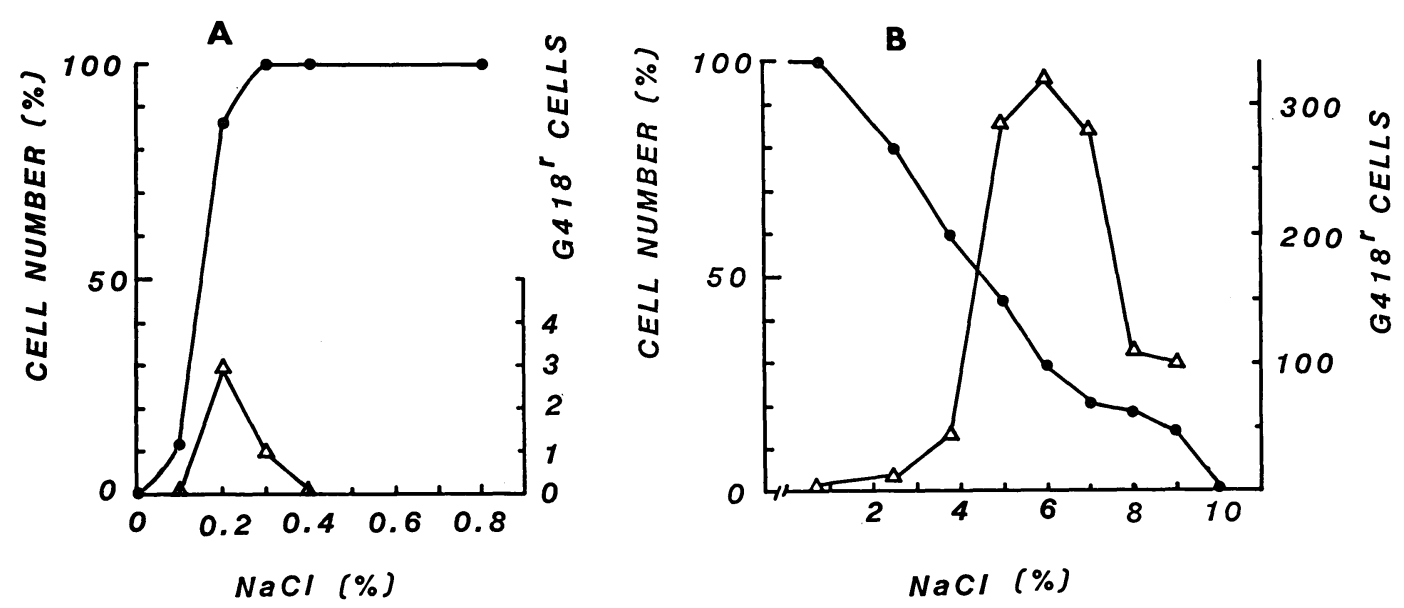

Fig. 1. Effect of $\mathrm{NaCl}$ concentration on cell growth and transfection frequency. The protocol of transfection with $5 \mu \mathrm{g}$ of linear pSV2neo and selection of the transformants were as described in Materials ANd Methods. After incubation with DNA plus polybrene for $6 \mathrm{~h}$, the cells were treated with Hanks' solution containing different concentrations of $\mathrm{NaCl}$ as shown in the figure. For determination of cell growth, $1 \times 10^{4}$ cells were incubated for 6 days and the cell number was determined. $\bullet$ : Cell number; $\triangle$ : number of transformants per $10^{6}$ cells.

studies, and $15-18 \%$ was practically the maximum concentration at which the cells survived. When the polybrene method with $15 \%$ DMSO was tested, the efficiency of transfection was $4.2 \times 10^{-5}$. To achieve more efficient transfection, we tested several other methods which may alter cell permeability to DNA. After incubation of cells with DNA plus polybrene for $6 \mathrm{~h}$, cells were treated either with a hypertonic solution $(5 \% \mathrm{NaCl}$ in $\mathrm{MEM})$, a method used to permeabilize cells to small molecules without loss of viability (4), or with a solution containing $50 \%$ polyethylene glycol (PEG), which has been used for cell fusion (20).

As shown in Table 1, treatment of cells with the hypertonic solution resulted in high-frequency transfection $\left(2.8 \times 10^{-4}\right)$. Treatment with PEG 6000 showed the same degree of transfection as $15 \%$ DMSO. By the standard method of DNA plus polybrene and $5 \% \mathrm{NaCl}$ treatment (MATERIALS AND METHODS), both linear and supercoiled DNA was taken up by the cells with similar efficiency. No transformant was produced without DNA or when the order of the protocol was reversed. When cells treated by the standard method were further treated with $10 \%$ DMSO or $50 \%$ PEG, the frequency of transfection was greatly reduced. Treatment of the cells with $5 \% \mathrm{NaCl}$ after incubation with DNA-calcium phosphate precipitates caused a several fold increase in the efficiency compared to treatment with $18 \%$ DMSO.

We next investigated the effect of various concentrations of $\mathrm{NaCl}$ on cell survival and transfection frequency. Figure 1 shows the results. When incubated for $20 \mathrm{~min}$ at $34^{\circ} \mathrm{C}, \mathrm{FM} 3 \mathrm{~A}$ cells resisted $\mathrm{NaCl}$ in a range of $0.1-9.0 \%$ in MEM. Cell viability was lost abruptly in the hypotonic solution at a concentration of $0.1 \%$ (Fig. 1A) and gradually under the hypertonic conditions (Fig. 1B). When the transfection was performed with different concentrations of $\mathrm{NaCl}$ after treatment with DNA plus polybrene, there was a small increase in efficiency with hypotonic solution, $3 \times 10^{-6}$ at $0.2 \% \mathrm{NaCl}$ (Fig. 1A), but the highest efficiency was obtained at $0.6 \% \mathrm{NaCl}(3.2 \times$ 


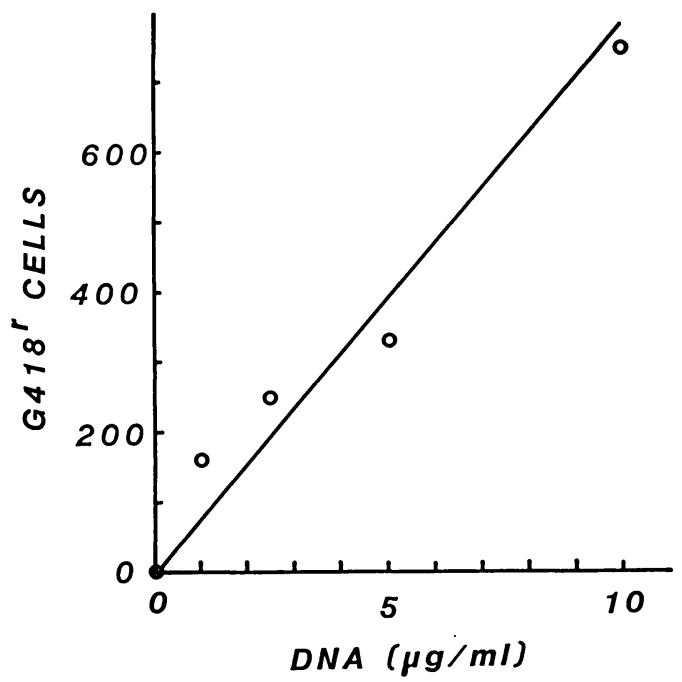

Fig. 2. Effect of DNA amounts on transfection frequency. Different amounts of linear pSV2neo DNA were used for transfection.

10-4) (Fig. 1B).

Under standard conditions, the frequency of transfection was proportional to the DNA dose, as shown in Fig. 2. These results indicate that carrier DNA was not required and transformation depended solely on the input DNA. At a dose of $10 \mu \mathrm{g}$ of plasmid DNA, a frequency of $7.5 \times 10^{-4}$ was obtained.

To test the stability of the transformed cells, independent colonies were transferred to the culture medium and first incubated with G418 for 2 weeks and then without

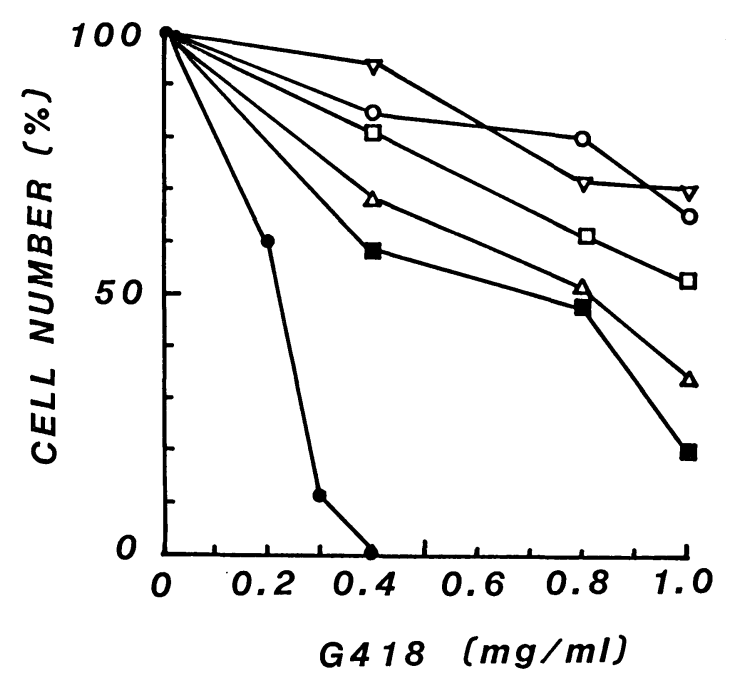

Fig. 3. Sensitivity of FM3A cells and transformed cells to G418. Cells were incubated for 6 days with different amounts of G418 and the cell number was determined. FM3A cells without transfection. Transformed cell clone, $\bigcirc:$ G-1; $\triangle:$ G-2; $\nabla:$ G-3; $\square:$ G-4 and $\mathbf{\square}:$ G-5. 


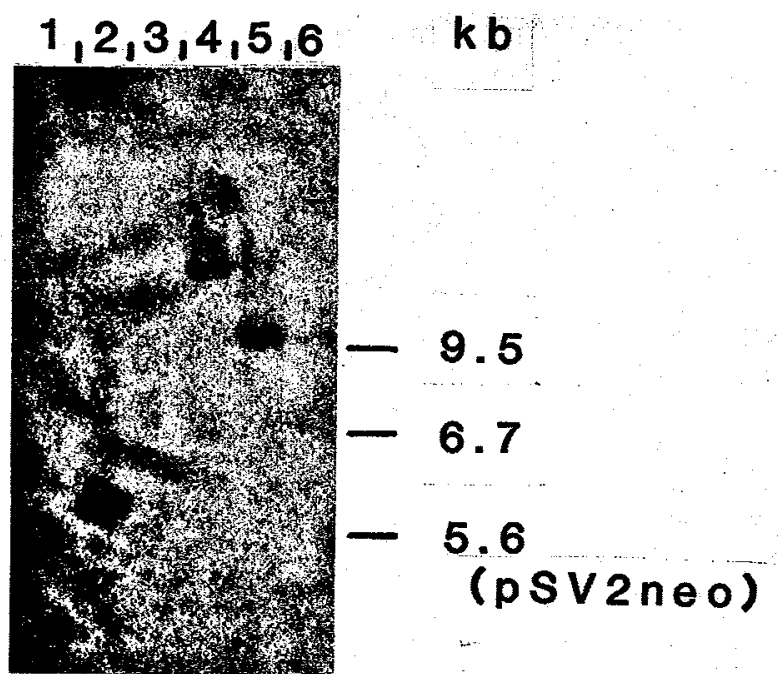

Fig. 4. Southern blot analysis of FM3A cells and transformants. Lane 1: DNA from FM3A cells without transfection; lanes 2-6: DNAs from transformed cell clones G-1 G-5, respectively.

the agent for 2 months. After this period, the sensitivity of these cell clones, termed G-1 G-5, to G418 was determined. Figure 3 shows the results. Growth of FM3A cells without transfection was completely inhibited at $0.4 \mathrm{mg} / \mathrm{ml}$ of $\mathrm{G} 418$. All five transformed cell clones showed increased resistance to G418. Transformed cell clones G-1 and G-3 were the most resistant while G-2 and G-5 were the most sensitive to the agent. The results showed that acquired resistance to G418 was stable for at least 2 months of incubation. These cell clones were used to detect plasmid DNA in the cells by Southern blot hybridization.

DNAs were extracted from these transformed cells and digested with restriction endonuclease EcoR1, the same enzyme used to linearize pSV2neo DNA before transfection. The membrane containing these DNA blots was hybridized to labeled plasmid DNA. The results are shown in Fig. 4. There was no signal of hybridization in lane 1, which contained FM3A cells without transfection. Lanes 2, 4, and 5, which contained the DNAs of G-1, -3 , and -4 cells, showed positive signals of hybridization. As seen from the autoradiogram, the position and intensity of the bands were all different among these cells. A dense band was observed at the position of $5.8 \mathrm{~kb}$ with G- 1 cells, and less dense bands at $15 \mathrm{~kb}$ and $9.6 \mathrm{~kb}$ with G-3 and -4 cells, respectively. The different intensities of the bands indicate that the cells contained different numbers of plasmid DNA copies. However, the G-2 and G-5 cells (lanes 3 and 6) did not show positive signals on the autoradiogram.

Acknowledgement. This work was supported in part by grants from the Ministry of Education, Science and Culture, Japan and a Research Promotion Grant, the Tokai University General Research Organization.

\section{REFERENCES}

1. Ayusawa, D., K. Iwata, T. Kozu, S. Ikegami and T. Seno. Increase in datP pool in aphidicolin-resistant mutants of mouse FM3A cells. Biochem. Biophys. Res. Commun. 91, 946954, 1979 
2. Ayusawa, D., K. Iwata and T. Seno. Conditional thymidine auxotrophic mutants of mouse FM3A cells due to thermosensitive thymidylate synthetase and their prototrophic revertants. J. Biol. Chem. 256, 12005-12012, 1981

3. Ayusawa, D., H. Koyama, K. Iwara and T. Seno. Selection of mammalian thymidine auxotrophic cell mutants defective in thymidylate synthetase by their reduced sensitivity to methotrexate. Somatic Cell Genet. 7, 523-534, 1981

4. Castellot, J.J., M.R. Miller and A.B. Pardee. Animal cells reversibly permeable to small molecules. Proc. Natl. Acad. Sci. U.S.4. 75, 351-355, 1978

5. Chaney, W.G., D.R. Howard, J.W. Polland, S. Sallustio and P. Stanley. High-frequency transfection of CHO cells using polybrene. Somatic Cell. Mol. Genet. 12, 237-244, 1986

6. Graham, F.L. and A.J. VAn Der Eb. A new technique for the assay of infectivity of human adenovirus 5 DNA. Virology, 52, 456-467, 1973

7. Hama-Inaba, H., T. Shiomi, K. Sato, A. Ito and M. Kasai. Electric pulse-mediated gene transfer in mammalian cells grown in suspension culture. Cell Struct. Funct. 11, 191-197, 1986

8. Hyodo, M. and K. Suzuki. A temperature-sensitive mutant isolated from mouse FM3A cells defective in DNA replication at a non-permissive temperature. Exp. Cell Res. 137, 31-38, 1982

9. Jariwalla, R.J., L. Aurelian and P.P.P. Ts'o. Immortalization and neoplastic transformation of normal diploid cells by defined cloned DNA fragments of Herpes simplex virus type 2. Proc. Natl. Acad. Sci. U.S.A. 80, 5902-5906, 1983

10. Jolly, D.J., H. Okayama, P. Berg, A.C. Esty, D. Filpula, P. Bohlen, G.G. Johnson, J.E. Shivelly, T. Hunkapillar and T. Friedmann. Isolation and characterization of a full-length expressible cDNA for human hypoxanthine phosphoribosyl transferase. Proc. Natl. Acad. Sci. U.S.A. 80, 477-481, 1983

11. KaWAi, S. and M. Nishizawa. New procedure for DNA transfection with polycation and dimethyl sulfoxide. Mol. Cell. Biol. 4, 1172-1174, 1984

12. Koyama, H. and H. Kodama. Adenosine phosphoribosyl transferase deficiency in cultured mouse mammary tumor FM3A cells resistant to 4-carbamoyl-imidazolium 5-olate. Cancer Res. 42, 4210-4214, 1982

13. Kuhn, L.C., A. MacClelland and F. Ruddle. Gene transfer, expression, and molecular cloning of the human transferrin receptor gene. Cell 37, 95-103, 1984

14. Lewis, W.H., P.R. Srinivasan, N. Stokoe and L. Siminovitch. Parameters governing the transfer of the genes thymidine kinase and dihydrofolate reductase into mouse cells using methaphase chromosomes or DNA. Somatic Cell Mol. Genet. 6, 333-347, 1980

15. Lin, P.F., S.U. ZhaO and F.H. RuddLE. Genomic cloning and preliminary characterization of the human thymidine kinase gene. Proc. Natl. Acad. Sci. U.S.A. 80, 6528-6532, 1983

16. Maniatis, T., E. Fritsch and J. Sambrook. Molecular Cloning: A Laboratory Manual, Cold Spring Harbor Laboratory, Cold Spring Harbor, New York, 1982

17. McCutchan, J.H. and J.S. Pagano. Enhancement of the infectivity of simian virus 40 deoxyribonucleic acid with diethylaminoethyl-dextran. J. Natl. Cancer Inst., 41, 351-357, 1968

18. Mukherjee, A.B., S. Orloff, J.D. Butler, T. Triche, P. Lalley and J.D. Schulman. Entrapment of methaphase chromosomes into phospholipid vesicles (lipochromosomes): carrier potential in gene transfer. Proc. Natl. Acad. Sci. U.S.A. 75, 1361-1365, 1978

19. Murakami, Y., H. Yasuda, H. Miyazawa, F. Hanaoka and M. Yamada. Characterization of a temperature-sensitive mutant of mouse FM3A cells defective in DNA replication. Proc. Natl. Acad. Sci. U.S.A., 82, 1761-1765, 1985

20. Pontecorvo, G. Production of mammalian somatic cell hybrids by means of polyethylene glycol treatment. Somatic Cell Genet. 1, 397-400, 1975

21. S.Andri-Goldin, R.M., A.L. Goldin, M. Levine and J.C. Glorioso. High-frequency transfer of cloned Herpes simplex virus type 1 sequences to mammalian cells by protoplast fusion. Mol. Cell. Biol. 1, 743-752, 1981

22. SHIH, C. and R.A. WeInBerg. Isolation of a transforming sequence from a human bladder carcinomal cell line. Cell 29, 161-169, 1982 
23. Southern, P.J. and P. Berg. Transformation of mammalian cell to antibiotic resistance with a bacterial gene under control of the SV40 early region promoter. J. Mol. Appl. Genet., 1, 327341,1982

24. Tsai, Y., F. Hanaoka, M.M. Nakano and M. Yamada. A mammalian DNA mutant decreasing nuclear DNA polymerase $\alpha$ activity at non-permissive temperature. Biochem. Biophys. Res. Commun., 91, 1190-1195, 1979

25. Yokota, T., L. Frank, D. Rennick, C. Hall, N. Arai, T. Mosmann, G. Nabel, H. Cantor and K. ARAI. Isolation and characterization of a mouse cDNA clone that expresses mast-cell growth factor activity in monkey cells. Proc. Natl. Acad. Sci. U.S.A. 81, 1070-1074, 1984

(Received for publication, September 16, 1987) 